\title{
Potent production of capsaicinoids and capsinoids by Capsicum peppers
}

Kenji Kobata, ${ }^{\dagger}{ }^{\ddagger}$ Mai Sugawara, ${ }^{\dagger}$ Makoto Mimura, ${ }^{\dagger}$ Susumu Yazawa, ${ }^{\S}$ and Tatsuo Watanabe ${ }^{*}+\dagger$

${ }^{\dagger}$ Graduate School of Integrated Pharmaceutical and Nutritional Sciences, University of Shizuoka, 52-1 Yada, Suruga-ku, Shizuoka 422-8526, Japan, ${ }^{\ddagger}$ Faculty of Pharmaceutical Sciences, Josai University, 1-1 Keyakidai, Sakado, Saitama 350-0295, Japan, and

${ }^{\S}$ Graduate School of Agriculture, Kyoto University, Oiwake-cho, Kitashirakawa, Kyoto 606-8502, Japan.

\section{Title running header:}

Capsicum peppers produce capsaicinoids and capsinoids

${ }^{*}$ To whom correspondence should be addressed. Tel: +81-54-264-5543. Fax:

+81-54-264-5550. E-mail: watanbt@u-shizuoka-ken.ac.jp. 


\section{ABSTRACT}

2

The fundamental structure of capsinoids is a fatty acid ester with vanillyl alcohol whereas in capsaicinoids a fatty acid amide is linked to vanillylamine. To clarify the relationship between their biosynthesis in Capsicum plants, we carried out an in vivo tracer experiment using stable isotopically-labeled putative precursors. LC-MS/MS was used to measure the uptake of isotopes into metabolites after injection of the labeled precursors into intact fruits of a pungent cultivar, Peru, and a nonpungent cultivar, CH-19 Sweet. Labeled vanillylamine was incorporated into capsaicinoids in both cultivars. While labeled vanillyl alcohol was incorporated into capsinoids in both cultivars, the accumulation of intact capsaicinoids in Peru was suppressed by over $60 \%$ after administration of vanillyl alcohol. In Peru, labeled vanillin was converted to both vanillylamine and, in 5-fold excess, vanillyl alcohol. Moreover, labeled vanillin was converted exclusively to vanillyl alcohol in $\mathrm{CH}-19$ Sweet. These data are consistent with the incorporation of labeled vanillin into capsaicinoids and capsinoids in both cultivars. We conclude that pungent cultivars are highly potent producers of vanillyl alcohol that is incorporated into capsinoids and that biosynthesis of capsinoids is catalyzed by capsaicin synthase.

KEYWORDS: Capsinoid; capsaicinoid; biosynthesis; vanillin; vanillylamine; vanillyl alcohol; Capsicum plants; in vivo tracer experiment; stable isotope; LC-MS/MS; putative aminotransferase; capsaicin synthase 
The fruits (peppers) of Capsicum plants, such as sweet pepper, are used as fresh

27 foodstuffs worldwide, while their processed products are used to make seasonings,

28 including hot peppers, that add color and spice to a variety of cuisines. Moreover, peppers have been traditionally used by certain societies for their stimulatory or analgesic properties. The substances responsible for the stimulatory properties (pungency) of peppers are a group of lipophilic alkaloids, the capsaicinoids. The fundamental structure of capsaicinoids is a branched-chain fatty acid amide of vanillylamine, and the major capsaicinoids in nature are capsaicin (CAP) and dihydrocapsaicin (DC) (Figure 1). Capsinoids represent a novel group of nonpungent capsaicinoid-like substances originally found in a nonpungent cultivar, C. annuum 'CH-19 Sweet' $(1,2)$, and subsequent studies have shown that many pungent Capsicum species contain capsinoids (3-6). Capsinoids are defined by a branched-chain fatty acid ester of vanillyl alcohol, and the major naturally occurring capsinoids in nature are capsiate (CST) and dihydrocapsiate (DCT) (Figure 1). The chemical structures of these species are similar to those of the major capsaicinoids, with the exception of the center linkage, which is an ester bond in capsinoids and an amide bond in capsaicinoids. Capsinoids have attracted attention for their capsaicinoid-like physiological and biological properties, and their lack of the harmful stimuli of capsaicinoids (7-9). Early classical in vivo tracer studies using radiolabeled precursors described the outline of the biosynthetic pathway of capsaicinoids (10), in which their aromatic moiety is derived from phenylalanine via the phenylpropanoid pathway, and their fatty acid moiety originates from branched amino acids via the fatty acid elongation pathway. 
Details of the downstream of these pathways however, where vanillin is converted to vanillylamine and the amine is subsequently condensed with a fatty acid to generate a capsaicinoid, remain to be clarified. Recent molecular biological approaches have suggested that the $p A M T$ gene of the pungent Capsicum fruits encodes a putative aminotransferase that catalyzes the conversion of vanillin to vanillylamine $(11,12)$. Furthermore, a putative acyltransferase (tentatively referred to as capsaicin synthase, CS) encoded by the Pun1 gene is regarded as a candidate enzyme catalyzing the condensation of vanillylamine with a fatty acid (13-16). Given their structural resemblance, the biosynthetic pathways of capsinoids and capsaicinoids are thought to be closely related. A previous in vivo tracer study in our group using radiolabeled precursors demonstrated that capsinoids are derived from vanillin via vanillyl alcohol in the fruits of $\mathrm{CH}-19$ Sweet (17). Figure 2 shows the proposed pathways for capsaicinoids and capsinoids biosyntheses. Although the conversion of vanillin to vanillyl alcohol and the condensation of the vanillyl alcohol with fatty acid are considered crucial for capsinoids biosynthesis, details regarding these reactions are 63 unclear. While molecular biological approaches would be complementary in understanding these pathways, defining the flow of metabolites represents a more direct approach to elucidating the biosynthetic pathways of these molecules. To achieve this goal, we describe here in vivo tracer experiments using stable isotopically-labeled compounds as putative precursors in the biosynthetic pathways of capsaicinoids and capsinoids. Labeled synthesized precursors were injected into the intact fruits of a capsaicinoid-rich (Peru) and a capsinoid-rich (CH-19 sweet) cultivars, after which the content of labeled metabolites in the fruits were measured using liquid chromatography-tandem mass 
MATERIALS AND METHODS

76

77

Materials

Stable isotopically-labeled precursors, $\left[1{ }^{\prime}-{ }^{13} \mathrm{C}\right]\left[5-{ }^{2} \mathrm{H}\right]$-vanillylamine,

$\left[1{ }^{\prime}-{ }^{13} \mathrm{C}\right]\left[5-{ }^{2} \mathrm{H}\right]$-vanillyl alcohol, $\left[1{ }^{\prime}-{ }^{13} \mathrm{C}\right]\left[5-{ }^{2} \mathrm{H}\right]$-vanillin, and $\left[1{ }^{\prime}-{ }^{13} \mathrm{C}\right]\left[5-{ }^{2} \mathrm{H}\right]-$ ferulic acid, were prepared as described in our previous study (18). Other reagents were purchased from Wako Chemicals (Osaka, Japan) and Sigma (St. Louis, MO).

82

83

Plants

84

Capsicum annuum L. cv. Peru (Peru) was used as a capsaicinoid-rich (pungent)

cultivar, and C. annuum L. cv. CH-19 Sweet (CH-19 Sweet) was used as a

86

capsinoid-rich (nonpungent) cultivar. Plants were cultured in the experiment farm of the

87 University of Shizuoka. Intact green color fruits 16-30 days after anthesis in Peru and 23-30 days in $\mathrm{CH}-19$ Sweet were used for the experiments.

89

\section{Administration of labeled precursors to intact Capsicum fruits}

For experiments measuring the conversion of capsaicinoids and capsinoids from labeled precursors, $12.5 \mu \mathrm{L} /$ day (50 $\mu \mathrm{L}$ in total) of $50 \mathrm{mM}$ labeled precursor in $50 \mathrm{mM}$ potassium phosphate buffer (KPB) solution (pH 6.8) was injected with a micro syringe

94 directly into the loculus of the fruit of an intact plant daily for 4 days. The fruit was

95 harvested a week after the first injection, then frozen in liquid nitrogen and stored at 
$96-20^{\circ} \mathrm{C}$ until analysis. For time course measurement of metabolites derived from the

97 labeled precursors, $15 \mu \mathrm{L}$ of $50 \mathrm{mM}$ labeled precursor in KPB was injected into a fruit

98 as described above. The fruit was harvested at $0,1,3$, and $24 \mathrm{~h}$ after the injection, then

99 frozen and stored. The same procedure was followed for control experiments except that

100 KPB only was injected.

101

102

Measurements of the metabolites

103

Stored fruits were freeze-dried and ground individually. To measure the

104 conversion of capsaicinoids and capsinoids from the labeled precursors, the ground

105 fruits were soaked in ethyl acetate. For time course measurement of metabolites, the

106 powdered fruits were soaked in methanol containing $0.1 \%$ acetic acid. The supernatant

107 was passed through $0.45 \mu \mathrm{m}$ pore membrane filter prior to application to an LC-MS/MS

108 system (LC: Nanospace SI-1, Shiseido, Tokyo, Japan; MS/MS: API 2000, Applied

109 Biosystems, Carlsbad, CA).

110 The LC-MS/MS conditions for measurements of capsaicinoids and capsinoids

111 were as follows: LC column, a reversed-phase silica gel column, Unison UK-C18, 2

112 mm i.d. x 150 mm (Imtakt Co., Kyoto, Japan); solvent, 50-100\% methanol containing

$1130.1 \%$ acetic acid (0-25 min); flow rate, $0.2 \mathrm{~mL} / \mathrm{min}$; injection volume, $5 \mu \mathrm{L}$; MS/MS,

114 ion source, ESI; polarity, positive; detection mode, multiple reaction monitoring

115 (MRM); detected ions, precursor/product, 306/137 for CAP [M], 308/139 for CAP

$116[\mathrm{M}+2], 308 / 137$ for DC [M], 310/139 for DC [M+2], 329/137 for CST [M], 331/139 for

117 CST [M+2], 331/137 for DCT [M], and 333/139 for DCT [M+2]. The ions of CAP, DC,

118 CST, and DCT were observed in the mass chromatogram at 14.5, 16.5, 20.7, and 22.4

119 min, respectively. The LC-MS/MS conditions for measurements of vanillylamine were 
as follows: LC column, a reversed-phase silica gel column, Fluofix 120E, 2 mm i.d. x

$121150 \mathrm{~mm}$ (Wako); solvent, 10-40\% methanol containing 0.1\% acetic acid (0-20 min);

122 flow rate, $0.2 \mathrm{~mL} / \mathrm{min}$; injection volume, $5 \mu \mathrm{L}$; MS/MS, ion source, APCI; polarity,

123 positive; detection mode, MRM; detected ions, precursor/product, 137/94 for

124 vanillylamine [M], and 139/96 for vanillylamine [M+2]. The ions of vanillylamine were

125 observed in the mass chromatogram at $5.8 \mathrm{~min}$. The LC-MS/MS conditions for

126 measurements of vanillyl alcohol were as follows: LC column, a reversed-phase silica

127 gel column, Unison UK-C18, 2 mm i.d. x 150 mm; solvent, 10-40\% methanol

128 containing $0.1 \%$ acetic acid (0-20 min); flow rate, $0.2 \mathrm{~mL} / \mathrm{min}$; injection volume, $5 \mu \mathrm{L}$;

129 MS/MS, ion source, APCI; polarity, positive; detection mode, MRM; detected ions,

130 precursor/product, 137/94 for vanillyl alcohol [M], 139/96 for vanillyl alcohol [M+2].

131 The ions of vanillyl alcohol were observed in the mass chromatogram at $9.8 \mathrm{~min}$.

132 The optimum parameters for the detection of each compound were tuned

133 automatically using authentic samples and Analyst software (Applied Biosystems). The

134 samples were analyzed in duplicate, and each compound was quantified using

135 calibration curves from the authentic samples.

136 The results quantified by the methods mentioned above were shown in Tables 1-3

137 and Figure 3. The conversion rates from labeled precursors into capsaicinoids and

138 capsinoids were calculated from the results shown in Tables 1-3 by an equation below,

139 and were summarized in Table 4.

140 Conversion rate $(\%)=$ a molar quantity of peculiarly increased $[\mathrm{M}+2]$ products at

141 a week after administration of a precursor / a molar quantity of the administered

142 precursor / 100.

143 
RESULTS

\section{Determination of capsaicinoids, capsinoids, and their precursors}

Each administered compound had a vanillyl moiety labeled with deuterium at its

149 aromatic 5-position and ${ }^{13} \mathrm{C}$ at its benzylic position, corresponding to a molecule 2 mass heavier [M+2] than the most abundant natural molecule [M]. Because these labeled positions are present in both capsaicinoids and capsinoids, the labeled compounds can

152 be followed by observing [M+2] molecules. Additionally, both capsaicinoids and

153 capsinoids have typical fragment ions generated by neutral gas collision against their

154 parent ions during mass spectroscopy. The fragment ions originating from the vanillyl moiety of capsaicinoids and capsinoids can be observed in the spectrum at $\mathrm{m} / \mathrm{z} 137$ for [M] molecules and $\mathrm{m} / \mathrm{z} 139$ for [M+2] molecules (18). In the present study, we

157 measured these metabolites with high selectivity and sensitivity using LC-MS/MS

158 within at least $10 \mathrm{pmol}$ of the quantitation limit, and observed significant alterations of

159 the levels of labeled precursors in intact Capsicum fruits. Although the abundance

160 values of $[\mathrm{M}+2]$ capsaicinoids and capsinoids $(\%[\mathrm{M}+2])$ in control samples measured in

161 this way were lower than the theoretical values, they were stable around $0.7 \%$. Increases

162 in these universal values in intact plants indicate that the labeled precursors have been

163 incorporated into capsaicinoids and capsinoids, and such increases were frequently

164 detected in this study (Tables 1-3).

165

166 Incorporation of labeled vanillylamine and vanillyl alcohol into capsaicinoids and 167 capsinoids in peppers 
Table 1 shows the isotope contents and abundance of capsaicinoids and capsinoids in the fruits of Capsicum plants 1 week after administration of [M+2] vanillylamine or [M+2] vanillyl alcohol. High levels of capsaicinoids (CAP and DC) were observed in all samples of the pungent cultivar, Peru. Levels of [M+2] capsaicinoids in Peru plants administered [M+2] vanillylamine were significantly higher than those in control Peru plants. Since the total quantities of the $[\mathrm{M}]$ and $[\mathrm{M}+2]$ capsaicinoids in both samples were almost equal, the abundance of [M+2] capsaicinoids $(\%[M+2])$ was calculated to be significantly larger in the administered sample than in the control, indicating that $[\mathrm{M}+2]$ vanillylamine was incorporated into [M+2] capsaicinoids in Peru. The conversion rate of [M+2] vanillylamine into [M+2] capsaicinoids was estimated at 1\% (Table 4). The administration of [M+2] vanillyl alcohol in Peru resulted in significant accumulations of [M+2] capsinoids (CST and DCT), with a conversion rate of approximately $2 \%$. Levels of the most abundant form of [M] capsaicinoids in Peru plants administered labeled vannilyl alcohol were significantly suppressed by over $60 \%$ compared with those in control and labeled vanillylamine-administered Perus. In the nonpungent CH-19 Sweet cultivar, the administration of [M+2] vanillylamine caused robust accumulation of [M+2] capsaicinoids at an estimated conversion rate of $0.3 \%$ (Table 4), despite the fact that [M+2] capsaicinoids were undetectable in other CH-19 Sweet samples. Significant increases in the levels of [M+2] capsinoids were observed after administration of [M+2] vanillyl alcohol in CH-19 Sweet, with an estimated conversion rate of $0.5 \%$.

\section{Incorporation of labeled vanillin and ferulic acid into capsaicinoids and capsinoids} in peppers 
Table 2 shows the effect of administration of [M+2] vanillin in both cultivars. In

$193[\mathrm{M}+2]$ vanillin-administered Peru, levels of [M+2] capsaicinoids and [M+2] capsinoids

194 were higher than those in control Peru plants, with conversion rates of approximately

$1951.6 \%$ and 3.0\%, respectively (Table 4). On the other hand, the total amounts of

196 capsaicinoids ([M] and $[\mathrm{M}+2])$ in the vanillin-administrated Peru tended to be lower

197 than those in control. Administration of [M+2] vanillin in CH-19 Sweet resulted in

198 significant increases in the levels of [M+2] capsinoids, at an estimated conversion rate

199 of $0.7 \%$. In contrast the conversion rate from vanillin to capsaicinoids was extremely

200 small (0.01\%). [M+2] ferulic acid administered in Peru plants was converted to

201 capsaicinoids and capsinoids (Table 3) at conversion rates of $0.8 \%$ and $0.1 \%$,

202 respectively. In contrast, in $\mathrm{CH}-19$ Sweet, conversion of [M+2] ferulic acid was

203 negligible.

204

\section{Conversion of labeled vanillin to vanillylamine and vanillyl alcohol in peppers}

Figure 3 shows the time course changes of vanillylamine and vanillyl alcohol levels after administration of [M+2] vanillin in Peru and CH-19 Sweet fruits. [M+2] vanillylamine increased immediately after the vanillin administration in Peru, and the maximum level was $36 \mu \mathrm{g} / \mathrm{g}$ dw fruits at $3 \mathrm{~h}$ post-administration, with a conversion rate estimated at 4\%. While vanillyl alcohol was present at only trace levels in control Peru,

211 levels of [M+2] vanillyl alcohol were again significantly increased by $3 \mathrm{~h}$ after the

212 vanillin administration to Peru. Maximal levels of [M+2] vanillyl alcohol were $170 \mu \mathrm{g} / \mathrm{g}$

$213 \mathrm{dw}$, with a conversion rate of $20 \%$, approximately 5 fold higher than in the case of

214 vanillylamine in Peru. The fruits of $\mathrm{CH}-19$ Sweet contained more than $450 \mu \mathrm{g} / \mathrm{g} \mathrm{dw}$ of

215 vanillyl alcohol naturally (0 h). Administration of [M+2] vanillin effected an increase of 
[M+2] vanillyl alcohol to $80 \mu \mathrm{g} / \mathrm{g}$ dw contents (conversion rate $=9.5 \%$ ) at $3 \mathrm{~h}$, after

217 which [M+2] vanillyl alcohol was undetectable at $24 \mathrm{~h}$. Negligible [M+2] vanillylamine

218 was observed after administration of [M+2] vanillin into $\mathrm{CH}-19$ Sweet, and native ([M])

219 vanillylamine was undetectable in samples of $\mathrm{CH}-19$ Sweet.

220

221

222

DISCUSSION

223

Here we showed that a pungent cultivar of pepper, which predominantly produces

capsaicinoids, also produces capsinoids, and that a nonpungent cultivar, which

226

predominantly synthesizes capsinoids, can also produce capsaicinoids. While trace

227

amounts of capsinoids have been previously detected in certain capsaicinoid-producing

228

cultivars (3-6), our study represents the first direct observation in peppers of the

229

production of capsinoids from their precursors, with the exception of phenylalanine and

valine. In both pungent and nonpungent cultivars, labeled vanillylamine and vanillyl

231

alcohol precursors were incorporated into capsaicinoids and capsinoids, respectively

232

(Table 1). Similar results were obtained after administration of vanillin (Table 2),

233

which is thought to represent a metabolic junction to vanillylamine or vanillyl alcohol

234

(Figure 2). Labeled vanillin was incorporated into both vanillylamine and vanillyl

alcohol in the pungent cultivar, Peru (Figure 3). The higher conversion of vanillin to

vanillyl alcohol than to vanillylamine, which we also observed in a previous radioactive

237

tracer study (17), may be due to excess amounts of the external vanillin. The

238

unexpected conversion of vanillin to vanillyl alcohol could conceivably result in the

239

significant production of capsinoids in Peru (Table 2). In CH-19 Sweet, incorporation 
of labeled vanillylamine into capsaicinoids was less efficient than in Peru, but was nevertheless significant (Table 1), while incorporation of labeled vanillin and ferulic

242 acid into capsaicinoids was undetectable (Tables 2-4). Moreover, vanillin was

243 converted to vanillyl alcohol, rather than vanillylamine (Figure 3). These results can be

244 explained by the disfunction in $\mathrm{CH}-19$ Sweet of a putative aminotransferase (pAMT)

245 (19-21), which catalyzes the conversion of vanillin into vanillylamine. The deficiency

246 of the vanillylamine is likely directly related to the low or non-existent levels of

247 capsaicinoids in $\mathrm{CH}-19$ Sweet.

248 Another important finding in our study relates to capsaicin synthase (CS), which 249 catalyzes the condensation of vanillylamine with a fatty acid to produce a capsaicinoid

250 (13-16). In the present study, accumulation of capsaicinoids in Peru was inhibited by over $60 \%$ by the administration of vanillyl alcohol (Table 1), prompting speculation that the administered alcohol may compete with native vanillylamine that is normally incorporated into capsaicinoids in a reaction catalyzed by CS. In the case of vanillin administration in Peru, in which both vanillylamine and vanillyl alcohol are produced

255 from the vanillin (Figure 3), similar competition was observed (Table 2), albeit to a 256 lesser extent. However, we failed to observe inhibition of capsinoid production by the 257 administration of vanillylamine in $\mathrm{CH}-19$ Sweet (Table 1). The large vanillyl alcohol 258 pool in intact CH-19 Sweet fruits (Figure 3) likely affected our results, in that levels of 259 labeled vanillylamine were insufficient to compete against the endogenous pool of 260 vanillyl alcohol. Moreover, the lower conversion rates of labeled precursors into their end products in $\mathrm{CH}-19$ Sweet compared to Peru (Table 4) may be due to the dilution of

262 precursors by this pool. Recently, Han et al. reported the potential role of the 263 CS-encoding Pun1 gene in the biosynthesis of capsinoids in peppers because capsinoids 
were present unexceptionally in cultivars of the CS genotype (6). CH-19 Sweet is also thought to belong to such a genotype (20). Suppression of pAMT by gene silencing has been shown to result in significant accumulation of capsinoids in a pungent pepper (19),

267 implying that CS catalyzed the production of capsinoids from vanillyl alcohol generated 268 instead of vanillylamine. CS possesses consensus motifs of certain plant acyl-transferases, some of which catalyze the reaction of benzyl alcohol with acyl-CoA to generate the corresponding esters $(15,22,23)$. In this context, the findings of our metabolic flow study provide additional evidence supporting the contribution of CS to capsinoid biosynthesis.

The rate of conversion of labeled vanillyl alcohol to capsinoids was approximately 274 double that of the conversion of labeled vanillylamine to capsaicinoids in both cultivars 275 (Table 4). A similar tendency was observed in the case of vanillin administration in Peru. Given that labeled vanillin was predominantly converted to vanillyl alcohol in Peru (Figure 3), the potential of CS for production of capsinoids may be similar to that 278 for production of capsaicinoids. We speculate therefore that the relative level of 279 capsaicinoids and capsinoids is a function of the levels of their direct precursors, vanillylamine and vanillyl alcohol, respectively. The factors determining the conversion of vanillin to vanillyl alcohol in peppers is not known at present.

\section{REFERENCES} substances, capsiate and dihydrocapsiate, from the fruits of a nonpungent 
cultivar, CH-19 Sweet, of pepper (Capsicum annuum L.). J. Agric. Food Chem. 1998, 46, 1695-1697.

2. Kobata, K.; Sutoh, K.; Todo, T.; Yazawa, S.; Iwai, K.; Watanabe, T. Nordihydrocapsiate, a new capsinoid from the fruits of a nonpungent pepper, Capsicum annuum. J. Nat. Prod. 1999, 62, 335-336.

3. Yazawa, S.; Yoneda, H.; Hosokawa, M.; Fushiki, T.; Watanabe, T. Novel capsaicinoid like substances in the fruits of new non-pungent cultivar ' $\mathrm{CH}-19$ Sweet’ of pepper (Capsicum annuum). Capsicum Eggplant Newslett. 2004, 23, $17-20$

4. Singh, S.; Jarret, R.; Russo, V.; Majetich, G.; Shimkus, J.; Bushway, R.; Perkins, B. Determination of capsinoids by HPLC-DAD in Capsicum species. J. Agric. Food Chem. 2009, 57, 3452-3457.

5. Tanaka, Y.; Hosokawa, M.; Otsu, K.; Watanabe, T.; Yazawa, S. Assessment of capsiconinoid composition, nonpungent capsaicinoid analogues, in Capsicum

6. Han, K.; Jeong, H.-J.; Sung, J.; Keum, Y. S.; Cho, M.-C.; Kim, J.-H.; Kwon, 304 J.-K.; Kim, B.-D.; Kang, B.-C. Biosynthesis of capsinoid is controlled by the Pun1 locus in pepper. Mol. Breeding 2013, 31, 537-548.

7. Macho, A.; Lucena, C.; Sancho, R.; Minassi, A.; Muñoz, E.; Appendino, G. Non-pungent capsaicinoids from sweet pepper. Synthesis and evaluation of the

8. $\quad$ Pyun, B.-J.; Choi, S.; Lee, Y.; Kim, T.-W.; Min, J.-K.; Kim, Y.; Kim, B.-D.; Kim, 

direct inhibition of Src kinase activity. Cancer Res. 2008, 68, 227-235.

313 9. Ludy, M.-J.; Moore, G. E.; Mattes, R. D. The effects of capsaicin and capsiate on energy balance: critical review and meta-analyses of studies in humans. Chem. Senses 2012, 37, 103-121.

10. Suzuki, T.; Iwai, K. Constituents of red pepper species: chemistry, biochemistry, pharmacology, and food science of the pungent principle of Capsicum species. In The Alkaloids Chemistry and Pharmacology, Brossi, A., Ed. Academic Press: New York, 1984, Vol. 23, pp 228-229.

11. Curry, J.; Aluru, M.; Mendoza, M.; Nevarez, J.; Melendrez, M.; O’Connell, M. A. Transcripts for possible capsaicinoid biosynthetic genes are differentially accumulated in pungent and non-pungent Capsicum spp. Plant Sci. 1999, 148, 
16. Stellari, G. M.; Mazourek, M.; Jahn, M. M. Contrasting modes for loss of pungency between cultivated and wild species of Capsicum. Heredity 2010, 104, 460-471.

17. Sutoh, K.; Kobata, K.; Yazawa, S.; Watanabe, T. Capsinoid is biosynthesized from phenylalanine and valine in a non-pungent pepper, Capsicum annuum L. cv. CH-19 sweet. Biosci. Biotechnol. Biochem. 2006, 70, 1513-1516.

18. Kobata, K.; Mimura, M.; Sugawara, M.; Watanabe, T. Synthesis of stable isotope-labeled precursors for the biosyntheses of capsaicinoids, capsinoids, and capsiconinoids. Biosci. Biotechnol. Biochem. 2011, 75, 1611-1614.

19. $\quad$ Lang, Y.; Kisaka, H.; Sugiyama, R.; Nomura, K.; Morita, A.; Watanabe, T.; Tanaka, Y.; Yazawa, S.; Miwa, T. Functional loss of pAMT results in biosynthesis of capsinoids, capsaicinoid analogs in Capsicum annuum cv. CH-19 Sweet. Plant J. 2009, 59, 953-961.

20. Tanaka, Y.; Hosokawa, M.; Miwa, T.; Watanabe, T.; Yazawa, S. Newly mutated putative-aminotransferase in nonpungent pepper (Capsicum annuum) results in biosynthesis of capsinoids, capsaicinoid analogues. J. Agric. Food Chem. 2010, $58,1761-1767$.

21. Tanaka, Y.; Hosokawa, M.; Miwa, T.; Watanabe, T.; Yazawa, S. Novel loss-of-function putative aminotransferase alleles cause biosynthesis of capsinoids, nonpungent capsaicinoid analogues, in mildly pungent chili peppers (Capsicum chinense). J. Agric. Food Chem. 2010, 58, 11762-11767.

22. Dudareva, N.; D’Auria, J. C.; Hee Nam, K.; Raguso, R. A.; Pichersky, E. Acetyl-CoA: benzylalcohol acetyltransferase - an enzyme involved in floral scent production in Clarkia breweri. Plant J. 1998, 14, 297-304. 
23. Yahyaoui, F. E. L.; Wongs-Aree, C.; Latché, A.; Hackett, R.; Grierson, D.; Pech, J. -C. Molecular and biochemical characteristics of a gene encoding an alcohol acyl-transferase involved in the generation of aroma volatile esters during melon ripening. Eur. J. Biochem. 2002, 269, 2359-2366.

364

365 Note: This work was supported by the Grant-in-Aid for Scientific Research (C)

366 (19580125) from the JPSP (Japan) and the Global Center of Excellence (COE) program 367 from the MEXT (Japan).

368 


\section{Figure Captions}

370

371 Figure 1. Chemical structures of capsaicinoids (capsaicin and dihydrocapsaicin) and

372 capsinoids (capsiate and dihydrocapsiate).

373

374 Figure 2. Proposed biosynthetic pathways of capsaicinoids and capsinoids.

375 pAMT, putative aminotransferase; CS, capsaicin synthase.

376

377 Figure 3. The time course change of contents of vanillylamine and vanillyl alcohol in

378 the fruits of peppers after administration of $\left[1{ }^{\prime}-{ }^{13} \mathrm{C}\right]\left[5-{ }^{2} \mathrm{H}\right]-\mathrm{vanillin}$.

379 Data are shown as means \pm S.E.M.

380

381 


\section{Table 1}

Isotope $([\mathrm{M}],[\mathrm{M}+2])$ contents $(\mu \mathrm{g} / \mathrm{g} d \mathrm{w}$ fruits) and abundance $(\%[\mathrm{M}+2])$ of capsaicinoids and capsinoids in the fruits of peppers cultivated with $\left[1{ }^{\prime}-{ }^{13} \mathrm{C}\right]\left[5-{ }^{2} \mathrm{H}\right]$-vanillylamine $\left(+\mathrm{VNH}_{2}\right)$, with $\left[1{ }^{\prime}-{ }^{13} \mathrm{C}\right]\left[5-{ }^{2} \mathrm{H}\right]$-vanillyl alcohol $(+\mathrm{VOH})$, or without any precursor $(\mathrm{Cont}$ ) for a week.

\begin{tabular}{|c|c|c|c|c|c|c|c|}
\hline & \multicolumn{3}{|c|}{ Peru } & \multicolumn{3}{|c|}{ CH-19 Sweet } \\
\hline & & Cont. $(n=3)$ & $+\mathrm{VNH}_{2}(\mathrm{n}=5)$ & $+\mathrm{VOH}(\mathrm{n}=6)$ & Cont. (n=6) & $+\mathrm{VNH}_{2}(\mathrm{n}=5)$ & $+\mathrm{VOH}(\mathrm{n}=6)$ \\
\hline CAP & $\begin{array}{c}{[\mathrm{M}]} \\
{[\mathrm{M}+2]} \\
(\%[\mathrm{M}+2])\end{array}$ & $\begin{array}{c}2213.6 \pm 238.8^{\mathrm{a}} \\
15.5 \pm 1.6^{\mathrm{a}} \\
(0.70 \pm 0.01)^{\mathrm{a}}\end{array}$ & $\begin{array}{c}1904.3 \pm 208.4^{\mathrm{a}} \\
38.3 \pm 6.2^{\mathrm{b}} \\
(2.18 \pm 0.52)^{\mathrm{b}}\end{array}$ & $\begin{array}{c}796.6 \pm 94.2^{\mathrm{b}} \\
8.6 \pm 1.1^{\mathrm{a}} \\
(1.12 \pm 0.11)^{\mathrm{ab}}\end{array}$ & $\begin{array}{l}5.2 \pm 0.5^{\mathrm{a}} \\
\text { nd } \\
(\mathrm{nc})\end{array}$ & $\begin{array}{c}7.8 \pm 0.3^{\mathrm{b}} \\
3.0 \pm 1.4 \\
(37.53 \pm 16.91)\end{array}$ & $\begin{array}{c}6.1 \pm 0.9^{\mathrm{ab}} \\
\text { nd } \\
\text { (nc) }\end{array}$ \\
\hline DC & $\begin{array}{c}{[\mathrm{M}]} \\
{[\mathrm{M}+2]} \\
(\%[\mathrm{M}+2])\end{array}$ & $\begin{array}{c}1250.2 \pm 154.2^{\mathrm{a}} \\
9.7 \pm 1.0^{\mathrm{a}} \\
(0.78 \pm 0.03)^{\mathrm{a}}\end{array}$ & $\begin{array}{c}1179.8 \pm 131.2^{\mathrm{a}} \\
45.2 \pm 10.5^{\mathrm{b}} \\
(4.13 \pm 1.16)^{\mathrm{b}}\end{array}$ & $\begin{array}{c}444.3 \pm 48.8^{\mathrm{b}} \\
8.7 \pm 1.1^{\mathrm{a}} \\
(2.04 \pm 0.26)^{\mathrm{ab}}\end{array}$ & $\begin{array}{c}5.7 \pm 0.6^{\mathrm{a}} \\
\text { nd } \\
(\mathrm{nc})\end{array}$ & $\begin{array}{c}7.7 \pm 0.4^{\mathrm{b}} \\
6.9 \pm 2.6 \\
(98.63 \pm 42.09)\end{array}$ & $\begin{array}{l}6.2 \pm 0.5^{\mathrm{ab}} \\
\text { nd } \\
\text { (nc) }\end{array}$ \\
\hline CST & $\begin{array}{c}{[\mathrm{M}]} \\
{[\mathrm{M}+2]} \\
(\%[\mathrm{M}+2])\end{array}$ & $\begin{array}{c}304.2 \pm 49.3^{\mathrm{a}} \\
\text { nd } \\
\text { (nc) }\end{array}$ & $\begin{array}{c}387.6 \pm 13.7^{\mathrm{a}} \\
\text { nd } \\
\text { (nc) }\end{array}$ & $\begin{array}{c}129.1 \pm 26.9^{\mathrm{b}} \\
86.4 \pm 16.5 \\
(72.87 \pm 17.55)\end{array}$ & $\begin{array}{c}1080.9 \pm 73.9^{\mathrm{a}} \\
7.4 \pm 0.7^{\mathrm{a}} \\
(0.68 \pm 0.02)^{\mathrm{a}}\end{array}$ & $\begin{array}{c}1291.8 \pm 55.2^{\mathrm{a}} \\
8.8 \pm 0.6^{\mathrm{a}} \\
(0.68 \pm 0.03)^{\mathrm{a}}\end{array}$ & $\begin{array}{c}1100.8 \pm 110.7^{\mathrm{a}} \\
14.6 \pm 2.3^{\mathrm{b}} \\
(1.30 \pm 0.11)^{\mathrm{b}}\end{array}$ \\
\hline DCT & $\begin{array}{c}{[\mathrm{M}]} \\
{[\mathrm{M}+2]} \\
(\%[\mathrm{M}+2])\end{array}$ & $\begin{array}{c}38.1 \pm 15.1^{\mathrm{a}} \\
\text { nd } \\
\text { (nc) }\end{array}$ & $\begin{array}{c}112.6 \pm 14.8^{b} \\
\text { nd } \\
\text { (nc) }\end{array}$ & $\begin{array}{c}35.2 \pm 8.4^{\mathrm{a}} \\
31.3 \pm 6.5 \\
(89.07 \pm 24.43)\end{array}$ & $\begin{array}{c}318.8 \pm 34.4^{\mathrm{a}} \\
\text { nd } \\
\text { (nc) }\end{array}$ & $\begin{array}{c}336.9 \pm 65.5^{\mathrm{a}} \\
\text { nd } \\
\text { (nc) }\end{array}$ & $\begin{array}{c}400.4 \pm 56.8^{\mathrm{a}} \\
7.6 \pm 1.2 \\
(1.93 \pm 0.23)\end{array}$ \\
\hline
\end{tabular}

CAP: capsaicin, DC: dihydrocapsaicin, CST: capsiate, DCT: dihydrocapsiate

nd: not detected, nc: not calculated

Data are shown as means \pm S.E.M.

Different letters indicate significant differences (Tukey's multiple-comparison test, $\mathrm{P}<0.05$ ). 


\section{Table 2}

Isotope $([\mathrm{M}],[\mathrm{M}+2])$ contents $(\mu \mathrm{g} / \mathrm{g}$ dw fruits) and abundance $(\%[\mathrm{M}+2]$ of capsaicinoids and capsinoids in the fruits of peppers cultured with $\left[1{ }^{\prime}-{ }^{13} \mathrm{C}\right]\left[5-{ }^{2} \mathrm{H}\right]$-vanillin $(+\mathrm{V})$ or without any precursor (Cont.) for a week.

\begin{tabular}{|c|c|c|c|c|c|}
\hline & \multicolumn{2}{|c|}{ Peru } & \multicolumn{2}{|c|}{ CH-19 Sweet } \\
\hline & & Cont. $(n=3)$ & $+V(n=5)$ & Cont. (n=6) & $+V(n=5)$ \\
\hline CAP & $\begin{array}{c}{[\mathrm{M}]} \\
{[\mathrm{M}+2]} \\
(\%[\mathrm{M}+2])\end{array}$ & $\begin{array}{c}2294.2 \pm 266.8 \\
16.2 \pm 2.0 \\
(0.70 \pm 0.01)\end{array}$ & $\begin{array}{c}1769.5 \pm 243.2 \\
34.7 \pm 2.8^{*} \\
(2.28 \pm 0.62)\end{array}$ & $\begin{array}{c}5.4 \pm 0.4 \\
\text { nd } \\
\text { (nc) }\end{array}$ & $\begin{array}{c}7.1 \pm 1.9 \\
0.2 \pm 0.1 \\
(2.69 \pm 1.23)\end{array}$ \\
\hline DC & $\begin{array}{c}{[\mathrm{M}]} \\
{[\mathrm{M}+2]} \\
(\%[\mathrm{M}+2])\end{array}$ & $\begin{array}{c}1613.1 \pm 150.2 \\
11.7 \pm 1.0 \\
(0.73 \pm 0.02)\end{array}$ & $\begin{array}{c}1111.2 \pm 144.6 \\
36.7 \pm 3.7^{*} \\
\left(3.70 \pm 0.87^{*}\right)\end{array}$ & $\begin{array}{c}4.5 \pm 0.4 \\
\text { nd } \\
\text { (nc) }\end{array}$ & $\begin{array}{c}6.8 \pm 1.6 \\
0.4 \pm 0.1 \\
(6.29 \pm 0.89)\end{array}$ \\
\hline CST & $\begin{array}{c}{[\mathrm{M}]} \\
{[\mathrm{M}+2]} \\
(\%[\mathrm{M}+2])\end{array}$ & $\begin{array}{c}247.7 \pm 46.1 \\
\text { nd } \\
\text { (nc) }\end{array}$ & $\begin{array}{c}192.1 \pm 33.3 \\
76.7 \pm 15.3 \\
(52.26 \pm 19.70)\end{array}$ & $\begin{array}{c}1230.1 \pm 87.1 \\
8.7 \pm 0.9 \\
(0.71 \pm 0.03)\end{array}$ & $\begin{array}{c}1593.8 \pm 129.3^{*} \\
30.9 \pm 4.6^{*} \\
\left(1.92 \pm 0.20^{*}\right)\end{array}$ \\
\hline DCT & $\begin{array}{c}{[\mathrm{M}]} \\
{[\mathrm{M}+2]} \\
(\%[\mathrm{M}+2])\end{array}$ & $\begin{array}{c}23.1 \pm 8.9 \\
\text { nd } \\
\text { (nc) }\end{array}$ & $\begin{array}{c}24.0 \pm 9.5 \\
31.0 \pm 18.1 \\
(104.04 \pm 21.43)\end{array}$ & $\begin{array}{c}360.2 \pm 45.2 \\
\text { nd } \\
\text { (nc) }\end{array}$ & $\begin{array}{c}720.9 \pm 17.9 * \\
16.9 \pm 2.9 \\
(2.35 \pm 0.43)\end{array}$ \\
\hline
\end{tabular}

CAP: capsaicin, DC: dihydrocapsaicin, CST: capsiate, DCT: dihydrocapsiate nd: not detected, nc: not calculated

Data are shown as means \pm S.E.M.

Significant differences (Student's t-test, * $\mathrm{P}<0.05$ ) against control (Cont.) 


\section{Table 3}

Isotope $([\mathrm{M}],[\mathrm{M}+2])$ contents $(\mu \mathrm{g} / \mathrm{g} \mathrm{dw})$ and abundance $(\%[\mathrm{M}+2])$ of capsaicinoids and capsinoids in the fruits of peppers cultured with $\left[1{ }^{\prime}-{ }^{13} \mathrm{C}\right]\left[5-{ }^{2} \mathrm{H}\right]$-ferulic acid $(+\mathrm{FA})$ or without any precursor (Cont.) for a week.

\begin{tabular}{|c|c|c|c|c|c|}
\hline & \multicolumn{2}{|c|}{ Peru } & \multicolumn{2}{|c|}{ CH-19 Sweet } \\
\hline & & Cont. $(n=6)$ & $+\mathrm{FA}(\mathrm{n}=7)$ & Cont. $(n=6)$ & $+F A(n=6)$ \\
\hline CAP & $\begin{array}{c}{[\mathrm{M}]} \\
{[\mathrm{M}+2]} \\
(\%[\mathrm{M}+2])\end{array}$ & $\begin{array}{c}2004.6 \pm 72.0 \\
8.9 \pm 0.7 \\
(0.64 \pm 0.01)\end{array}$ & $\begin{array}{c}1710.5 \pm 108.9 \\
15.7 \pm 1.9 \\
(0.91 \pm 0.09 *)\end{array}$ & $\begin{array}{c}5.0 \pm 0.6 \\
\text { nd } \\
(\mathrm{nc})\end{array}$ & $\begin{array}{c}6.7 \pm 0.4^{*} \\
\text { nd } \\
(\mathrm{nc})\end{array}$ \\
\hline DC & $\begin{array}{c}{[\mathrm{M}]} \\
{[\mathrm{M}+2]} \\
(\%[\mathrm{M}+2])\end{array}$ & $\begin{array}{c}1186.4 \pm 89.4 \\
9.8 \pm 0.6 \\
(0.75 \pm 0.01)\end{array}$ & $\begin{array}{c}1085.6 \pm 64.5 \\
23.9 \pm 4.3^{*} \\
(2.18 \pm 0.38 *)\end{array}$ & $\begin{array}{c}5.0 \pm 0.5 \\
\text { nd } \\
\text { (nc) }\end{array}$ & $\begin{array}{c}9.2 \pm 0.2^{*} \\
\text { nd } \\
(\mathrm{nc})\end{array}$ \\
\hline CST & $\begin{array}{c}{[\mathrm{M}]} \\
{[\mathrm{M}+2]} \\
(\%[\mathrm{M}+2])\end{array}$ & $\begin{array}{c}240.0 \pm 15.7 \\
\text { nd } \\
(n c)\end{array}$ & $\begin{array}{c}261.5 \pm 22.3 \\
4.8 \pm 1.3 \\
(1.95 \pm 0.56)\end{array}$ & $\begin{array}{c}1100.0 \pm 93.8 \\
6.8 \pm 0.8 \\
(0.62 \pm 0.03)\end{array}$ & $\begin{array}{c}1174.9 \pm 90.5 \\
8.2 \pm 1.7 \\
(0.68 \pm 0.09)\end{array}$ \\
\hline $\mathrm{DCT}$ & $\begin{array}{c}{[\mathrm{M}]} \\
{[\mathrm{M}+2]} \\
(\%[\mathrm{M}+2])\end{array}$ & $\begin{array}{c}26.5 \pm 1.6 \\
\text { nd } \\
\text { (nc) }\end{array}$ & $\begin{array}{c}26.3 \pm 2.0 \\
\text { nd } \\
\text { (nc) }\end{array}$ & $\begin{array}{c}408.5 \pm 56.1 \\
\text { nd } \\
\text { (nc) }\end{array}$ & $\begin{array}{c}698.8 \pm 73.6^{*} \\
\text { nd } \\
\text { (nc) }\end{array}$ \\
\hline
\end{tabular}

CAP: capsaicin, DC: dihydrocapsaicin, CST: capsiate, DCT: dihydrocapsiate nd: not detected, nc: not calculated

Data are shown as means \pm S.E.M.

Significant differences (Student's t-test, * $\mathrm{P}<0.05$ ) against control (Cont.) 


\section{Table 4}

Conversion rate (\%) from administered precursors to capsaicinoids (CAPs) and capsinoids (CSTs) for a week.

\begin{tabular}{c|cc}
\hline & $\begin{array}{c}\text { Peru } \\
(\mathrm{n}=5-7)\end{array}$ & $\begin{array}{c}\text { CH-19 Sweet } \\
(\mathrm{n}=5-6)\end{array}$ \\
\hline $\mathrm{VNH}{ }_{2} \rightarrow$ CAPs & $0.97 \pm 0.25$ & $0.29 \pm 0.09$ \\
$\mathrm{VOH} \rightarrow$ CSTs & $1.97 \pm 0.47$ & $0.54 \pm 0.09$ \\
$\mathrm{~V} \rightarrow$ CAPs & $1.56 \pm 0.18$ & $0.01 \pm 0.00$ \\
$\mathrm{~V} \rightarrow$ CSTs & $3.04 \pm 0.82$ & $0.69 \pm 0.15$ \\
$\mathrm{FA} \rightarrow$ CAPs & $0.84 \pm 0.21$ & $0.00 \pm 0.00$ \\
$\mathrm{FA} \rightarrow$ CSTs & $0.12 \pm 0.05$ & $0.03 \pm 0.05$ \\
\hline
\end{tabular}

CAPs: capsaicin + dihydrocapsaicin, CSTs: capsiate + dihydrocapsiate, $\mathrm{VNH}_{2}$ : vanillylamine, VOH: vanillyl alcohol, V: vanillin, FA: ferulic acid 


\section{Figure 1}
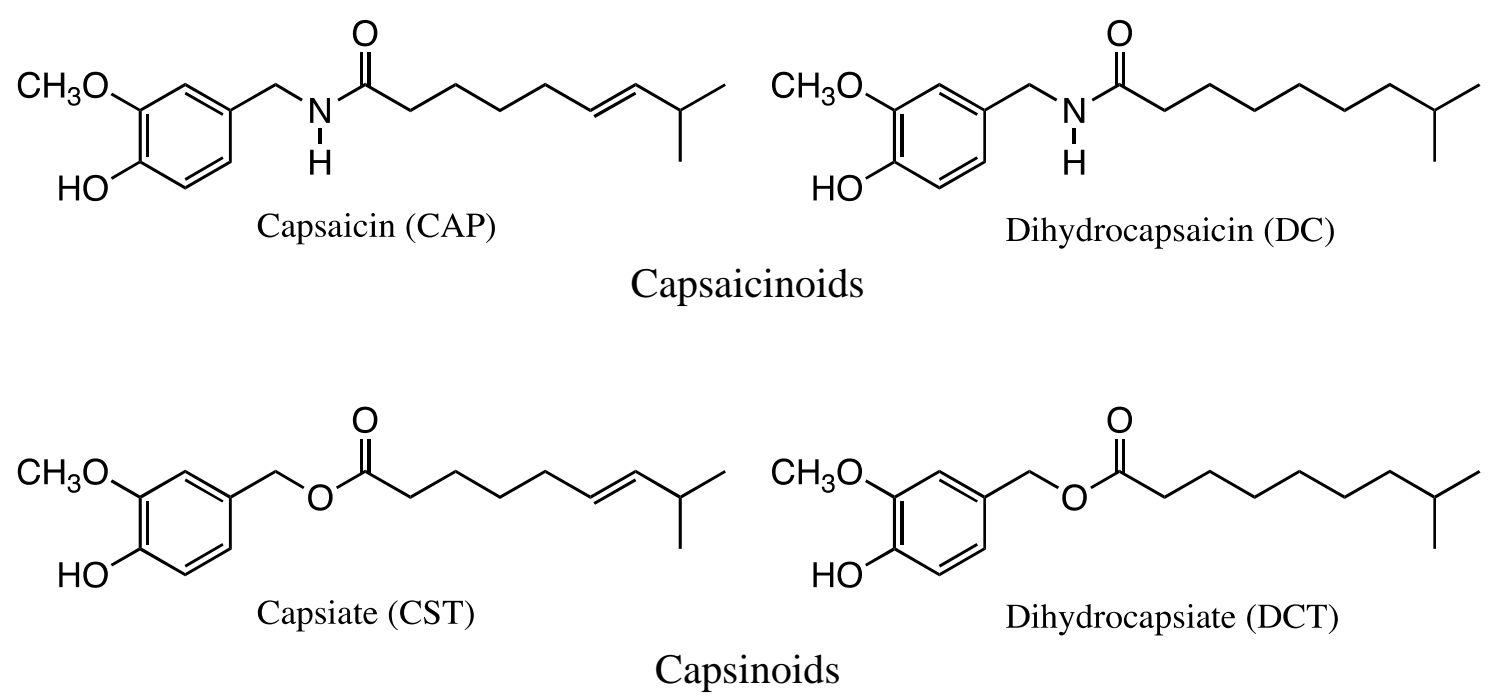


\section{Figure 2}

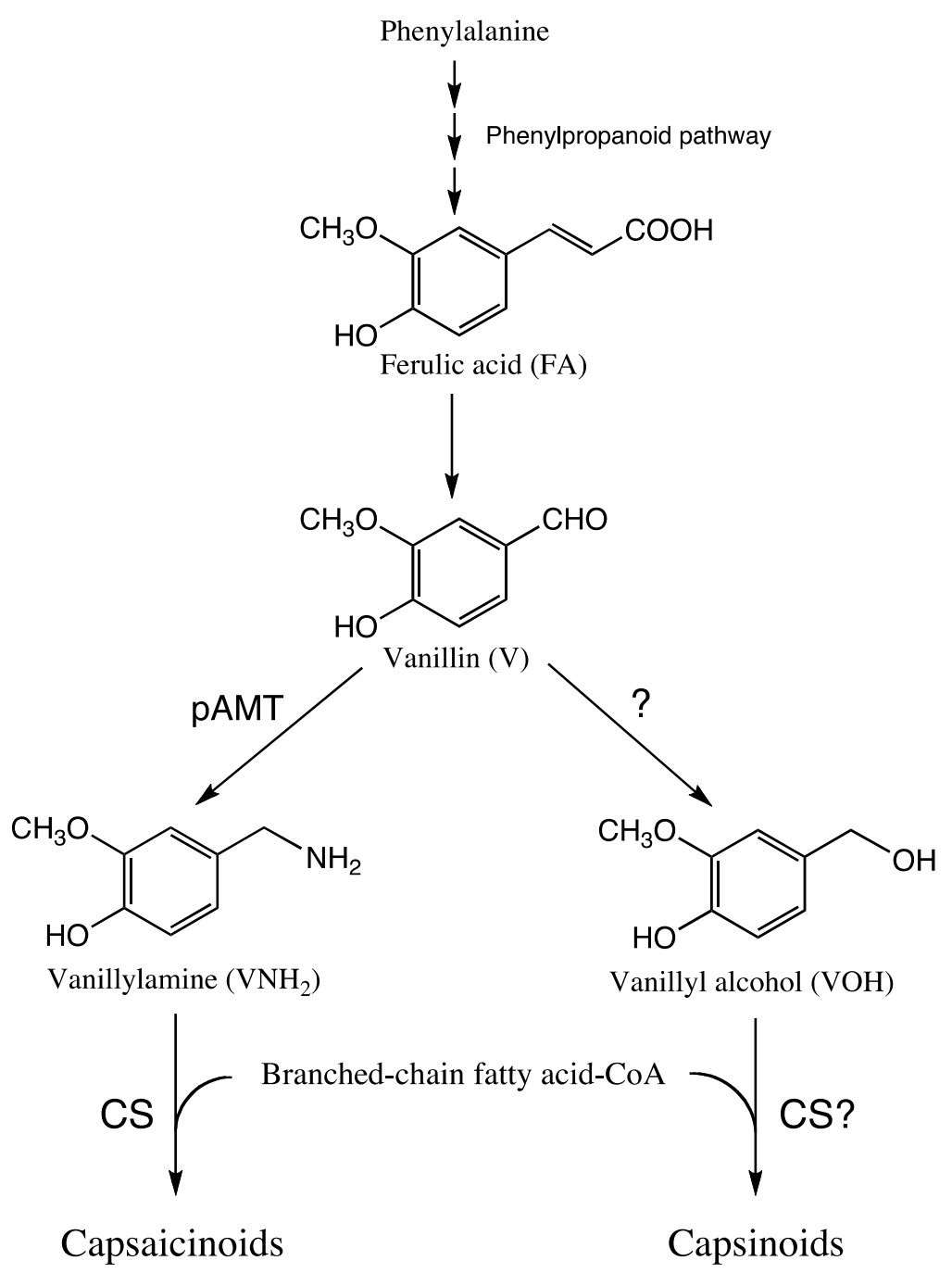


Figure 3
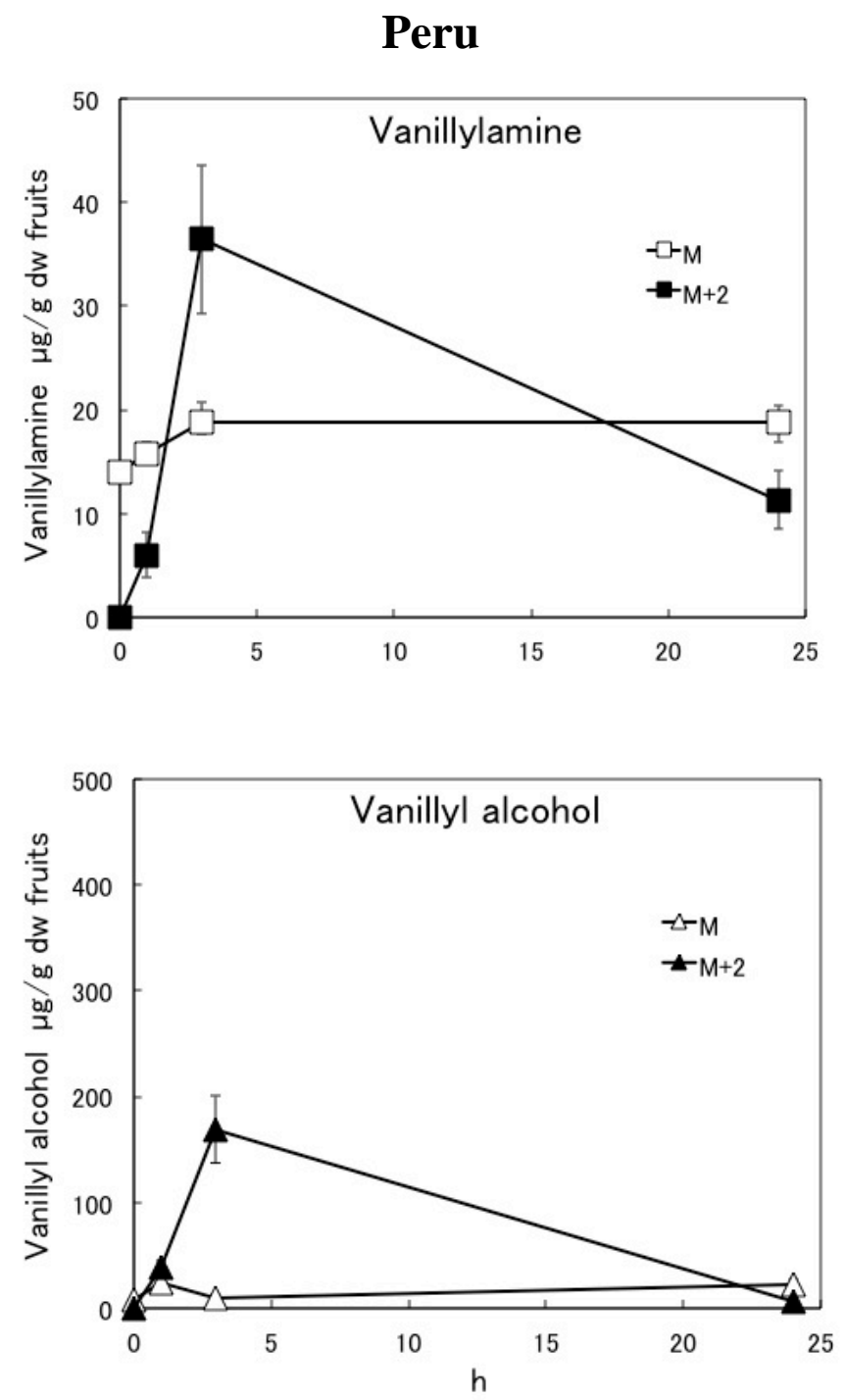
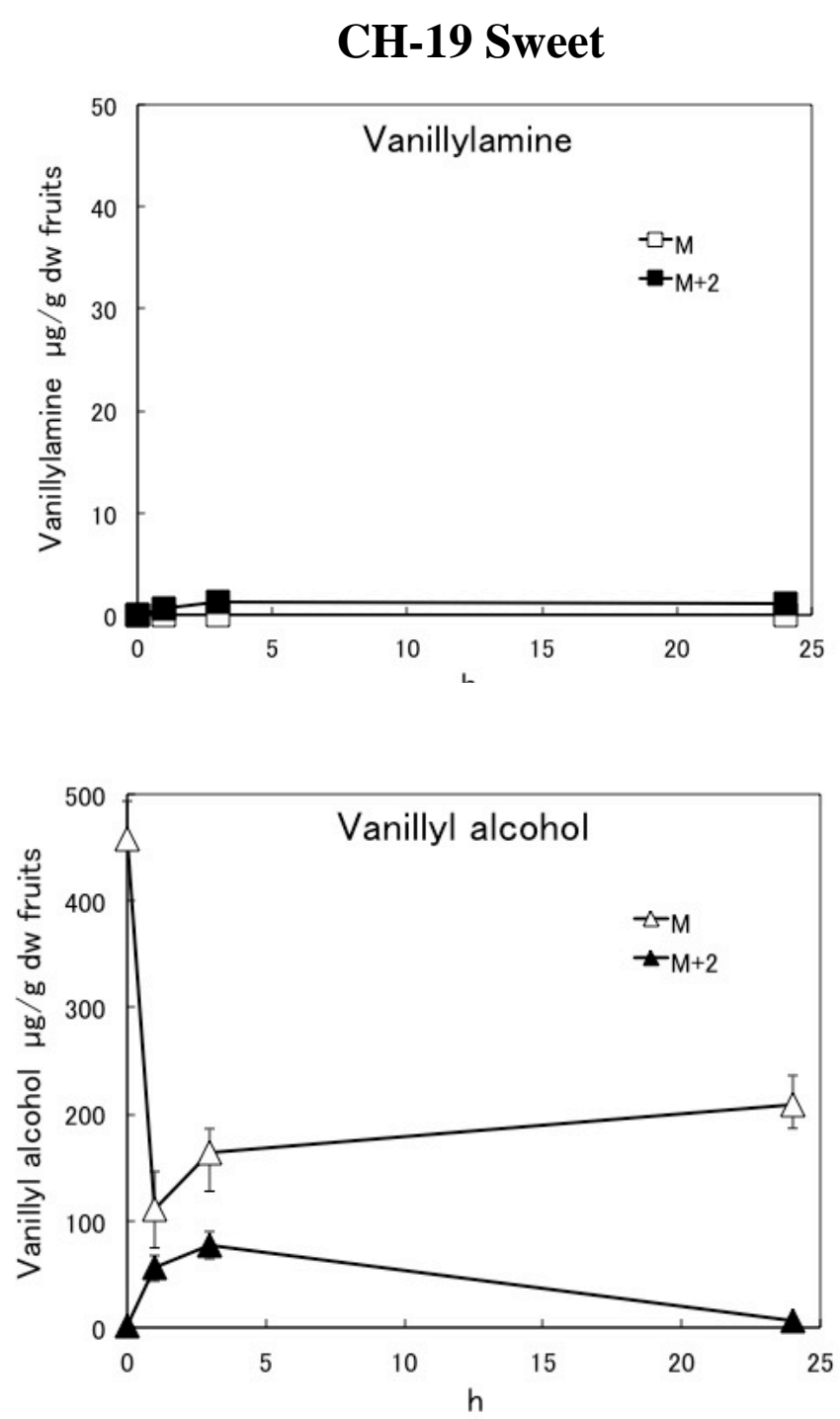


\section{TOC Graphic}

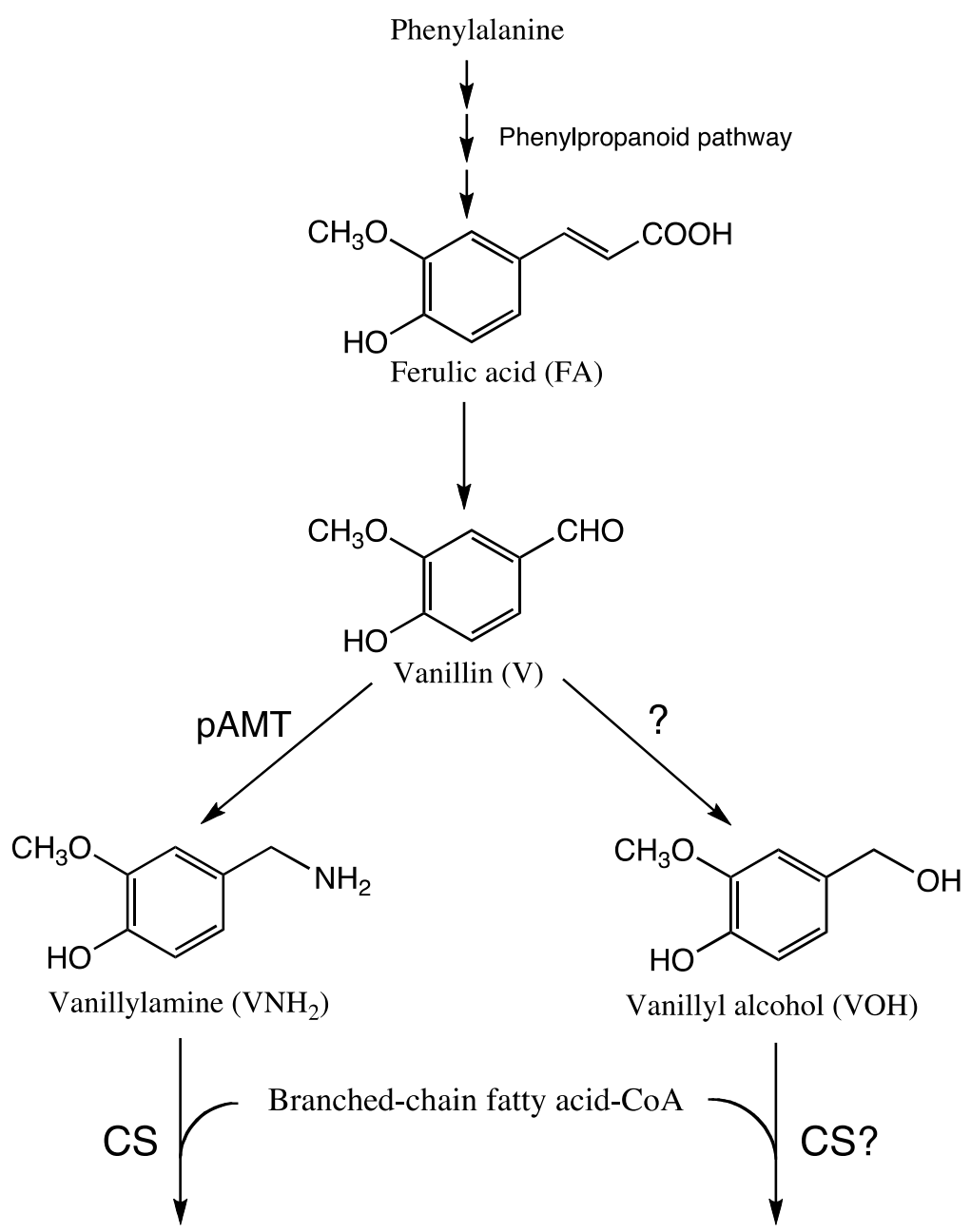

Capsaicinoids

Capsinoids 